\title{
La Escuela Primaria Cuauhtémoc, una escuela eficaz en el centro de la comunidad El Bethí, Hidalgo, México
}

\section{Cuauhtemoc Elementary School, an effective school at the center of the El Bethi community, Hidalgo, Mexico}

DOI: https://doi.org/10.32870/dse.v0i23.798

José María Duarte Cruz*

Giovanna Valenti Nigrini**

\begin{abstract}
Resumen
Esta investigación explora los factores asociados al buen desempeño académico estudiantil de una escuela de enseñanza primaria pública ubicada en la comunidad otomí El Bethí, en el estado de Hidalgo, México. Los estudiantes de esta institución registraron un desempeño académico sobresaliente en tres evaluaciones nacionales: Enlace 2012, Planea 2015 y 2016; por ello, y por su ubicación en un contexto socioeconómico marginado, es identificada como una escuela eficaz. Desde un enfoque cualitativo se desarrolló un estudio de caso para indagar cómo la gestión institucional, el involucramiento docente y el familiar se amalgaman para el logro escolar sostenido. Se emplearon herramientas analíticas de la sociología organizacional y del interaccionismo simbólico. Algunos hallazgos indican que la gestión educativa en esta escuela está basada en un modelo directivo de liderazgo distribuido, horizontal y centrado en las personas, se prioriza la comunicación y el respeto entre todos. Los docentes mantienen arraigo en la región, están comprometidos con su trabajo, hay un interés genuino por la preservación de la cultura indígena y por mejorar continuamente los aprendizajes. Se observa una corresponsabilidad de los padres y madres de familias, elevados niveles de participación, identificación y apropiación del espacio escolar como lugar público-comunitario de gran valor.
\end{abstract}

Palabras clave: escuela eficaz - gestión escolar - clima escolar - pertenencia - identidad escolar - identidad étnica.

\section{Abstract}

This research work explores factors associated with good academic performance of students in a public elementary school located in the Otomí community of El Bethí in the state of Hidalgo, Mexico. Students from this institution had an outstanding academic performance in three national assessments: Enlace 2012, Planea 2015, and 2016. For this reason and because of its location in a marginalized socioecono-

\footnotetext{
* Doctor en Filosofía con Orientación en Trabajo Social y Políticas Comparadas de Bienestar Social. Profesor Investigador. Líneas de investigación: Dimensiones de la violencia escolar, educación para la paz, género y educación. Departamento de Política y Cultura. Cátedra CONACYT-Universidad Autónoma Metropolitana-Xochimilco. México. duartecruz2911@hotmail.com

** Doctora en Ciencias Sociales. Líneas de investigación: educación, desarrollo, políticas públicas y mundo de trabajo. Profesora Investigadora. Departamento de Política y Cultura. Universidad Autónoma Metropolitana-Xochimilco. México. gvalenti@correo.xoc.uam.mx
} 
mic context, the school is identified as effective. A qualitative case study approach, with analytical tools from organizational sociology and symbolic interactionism was developed to find out how institutional management, teacher involvement, and family involvement combine to attain sustained school achievement. Some of our findings indicate that educational management in this school is based on a directive model of distributed, horizontal and people-centered leadership, prioritizing communication and respect among all. Teachers with deep roots in the region and committed to their work have a genuine interest in preserving indigenous culture and continuously improving learning, together with co-responsibility from the students' parents, high levels of participation, as well as identification and appropriation of the school space as a public-community place of great value.

Key words: effective school - school management - school climate - belonging - school identity - ethnic identity.

\section{Los estudios sobre escuelas eficaces}

La investigación sobre escuelas eficaces se origina en los años setenta del siglo pasado, principalmente en el contexto anglosajón, y más adelante cobraría relevancia en Iberoamérica. Dentro de ella se han generado diversos acercamientos explicativos al fenómeno de la eficacia en las escuelas, entendida como "aquella que promueve de forma duradera el desarrollo integral de todos y cada uno de sus estudiantes, más allá de lo que sería previsible teniendo en cuenta su rendimiento previo y la situación socio-económica y cultural de sus familias" (Murillo, 2005 citado en Hernández et al., 2014).

Dentro de estos acercamientos destacan los estudios realizados por Bellei et al., (2004); Hernández et al., (2014); Murillo, (2006), que han sentado bases teóricas y metodológicas relevantes entre las que destacan la definición misma de escuela eficaz, el empleo de sólidas propuestas metodológicas que han llevado al establecimiento de una serie de factores clave para que las escuelas funcionen eficazmente, así como para aquellas que no lo hacen. ${ }^{1}$

Algunas investigaciones hacen énfasis en la importancia de acercarse cualitativamente a las escuelas eficaces, e indagar en aquellos factores que hacen que un centro educativo obtenga buenos resultados a pesar de enfrentar situaciones adversas que, desde una mirada cuantitativa, estarían determinando un menor rendimiento o eficacia frente a sus pares con mejores condiciones económicas y sociales.

El concepto de escuelas eficaces, desde esta perspectiva, busca poner en el foco a los centros escolares y sus actores como los principales agentes educativos, capaces de trascender las

1 Estos factores clave son: $a$ ) sentido de comunidad; $b$ ) liderazgo educativo; $c$ ) clima escolar y de aula; $d$ ) altas expectativas; $e$ ) calidad del currículo y las estrategias de enseñanza; $f$ ) organización del aula; $g$ ) seguimiento y evaluación; $h$ ) desarrollo profesional de los docentes, entendido tanto como actitud hacia el aprendizaje continuo y la innovación; i) implicación de las familias; y $j$ ) instalaciones y recursos (Hernández et al., 2014:105). 
determinantes socioeconómicas o condicionamientos estructurales que limitarían el logro académico y el desempeño social, económico y cultural de sus estudiantes, lo que las convierte en escuelas atípicas. También destaca que la eficacia escolar se traduce no solo en el desempeño académico de los estudiantes, que puede identificarse a través de diferentes modelos de medición o pruebas estandarizadas, sino en la formación de ciudadanía, de capital social y humano dentro de las escuelas, aun cuando enfrentan múltiples desventajas (Báez, 1994).

En México, las evaluaciones al desempeño académico constatan los resultados de las pruebas e investigaciones internacionales; los sectores de población menos favorecidos son los que presentan resultados más bajos en los exámenes tanto nacionales como internacionales (INEE, 2014). En este marco, Acevedo et al., (2017) sostienen que la gestión institucional, el involucramiento docente y el involucramiento de padres y madres de familia en la escuela son factores que tienen efectos positivos (directos e indirectos) en el desempeño escolar.

En este sentido, y partiendo del reconocimiento de que las escuelas son productoras de sus propias dinámicas y procesos, son capaces de dar resultados que se alejan de este comportamiento típico y de que existen factores, como los que identifican Acevedo et al., (2017), que pueden incidir en el mejoramiento del desempeño académico de sus estudiantes; persiste la necesidad de identificar claves y aprendizajes que abonen a la comprensión de las escuelas como unidad compleja y multidimensional de análisis, así como contribuir con evidencia a una mejor toma de decisiones en materia educativa. Este estudio de caso se sitúa en esta posición y se dirige a dichos objetivos.

\section{Marco teórico-analítico}

\section{Factores relevantes de la organización escolar que inciden en el desempeño} de los estudiantes

Por gestión institucional Acevedo et al., (2017) hacen referencia a las acciones de gestión que de forma directa involucran al directivo en la evaluación y en el monitoreo de las actividades de enseñanza y aprendizaje que lleva a cabo el docente al interior del aula; aquellas que deben tener como eje lograr que los agentes escolares se reúnan entre ellos, discutan y lleguen a acuerdos respecto a temas pedagógicos; y aquellas de carácter más organizacional.

El involucramiento docente está relacionado con el papel del profesorado en la escuela y sus acciones específicas en el aula. Es, de acuerdo a diferentes investigaciones nacionales e internacionales, el factor que más influye positivamente en el desempeño académico de los estudiantes (Bellei et al., 2004, 2014; Hernández et al., 2014; Martínez, 2015; Martínez, Murillo, 2016; Martínez, 2012). Algunas acciones específicas que lo caracterizan son:

Planificación de las clases, generar un ambiente de disciplina, conocer la situación particular de cada estudiante respecto de su avance en el proceso de aprendizaje, preocupación para que éstos se moti-

Diólo@os sobre Educación 
ven, aprendan, se expresen y encuentren sentido al conocimiento que se busca entregar, y llevar a cabo un feedback o retroalimentación constante para lograr los objetivos de aprendizaje que se han hecho explícitos a los estudiantes (Acevedo et al., 2017: 61).

El involucramiento familiar comprende la participación de madres y padres de familia en las actividades escolares que van desde las institucionalmente establecidas, como la asistencia a juntas escolares, la revisión periódica y validación de las calificaciones obtenidas por sus hijos e hijas y la participación en el comité de padres y madres de familia, hasta actividades informales como la generación de recursos extraordinarios para la escuela a través de rifas, venta de alimentos, etcétera.

\section{Marco analítico para el estudio cualitativo de estos factores}

Para explorar estos tres factores desde un enfoque cualitativo, recurrimos al marco analítico que provee Blanco (2009), quien propone abordar la organización escolar en tres niveles de análisis: 1) el nivel externo o macro: comunidad, entorno, políticas y programas; 2 ) nivel meso: acuerdos y negociaciones a nivel escolar y de aula; y 3) nivel micro: coincidencia de objetivos, valores, motivaciones, expectativas que se dan a través de los intercambios cara a cara entre los agentes escolares.

En este trabajo nos enfocamos en el análisis de los niveles meso y micro de los tres factores y empleamos el nivel macro como contexto en el que se sitúan los otros niveles. Para el análisis del nivel meso se identificaron las prácticas recabadas en los discursos de los actores entrevistados, relacionadas con los acuerdos, negociaciones y conflictos que tienen lugar en el espacio escolar y referidas específicamente al rol directivo, al rol docente y al rol de los padres y madres de familia.

Para el análisis del nivel micro, partimos del concepto de rituales de interacción elaborado por Goffman (1970), y desarrollado por Collins, (2009). Este último llama rituales de interacción a "patrones de conducta repetitivos que constriñen al individuo generando en él un compromiso emocional hacia los símbolos que implican" (Collins, 2009: 64). Los rituales de interacción como herramienta analítica nos permiten explorar cómo se construyeron las actitudes, valores y objetivos comunes, así como la generación de sentimientos de identificación, membresía y compromiso con el grupo o con los elementos que lo componen. Desde este posicionamiento, estos elementos, que son comunes y que están presentes en las interacciones de los agentes escolares, son los insumos sobre los que se configuran las prácticas escolares exitosas. En otras palabras, son la base sobre la que se construyen los acuerdos, negociaciones y conflictos que se expresan en prácticas identificables en el nivel meso.

De este modo, se elaboró un conjunto de preguntas sobre las interacciones entre los actores clave de los tres factores relevantes, que son objeto de este estudio, con el propósito de 
identificar en los intercambios los objetivos, valores, expectativas y motivaciones comunes que los llevan directamente a comprometerse con la ejecución de las prácticas descritas en el nivel meso. Estas preguntas son: ¿Cómo son las interacciones entre el directivo, el colectivo docente, los padres y madres de familia?, ¿cómo son las interacciones entre docentes y estudiantes?, ¿cómo se involucran los docentes en tareas fuera del aula?, ¿cómo es, desde su perspectiva, su práctica docente?, ¿qué tipo de interacciones se da entre padres, madres de familia y los actores institucionales relevantes (administrativos y docentes)?

\section{Aspectos generales de la metodología}

Este estudio de caso forma parte de un proyecto de investigación más amplio, ${ }^{2}$ dentro del cual se realizó una primera identificación de escuelas primarias públicas en México aplicando el criterio del resultado en las mediciones de las pruebas Enlace 2012; Planea 2015 y 2016. Con este criterio se identificó a un grupo de escuelas con promedios generales por encima de la media nacional que mantuvieran estos resultados en las tres evaluaciones; luego, identificamos aquellas que enfrentan situaciones de desventajas estructurales.

La muestra final de escuelas denominadas "eficaces" se conformó de centros educativos en localidades cuyo Índice de Desarrollo Humano (IDH) es bajo y el Índice de Rezago Social (IRS) es alto. Dentro de este grupo de escuelas se encuentra la Primaria Cuauhtémoc, objeto de este estudio de caso y en donde se emplearon técnicas como la entrevista semiestructurada, el grupo focal y la observación no participante para recabar información cualitativa.

En el trabajo de campo se hicieron dos visitas a la escuela, donde se recabaron quince entrevistas con el personal docente, directivo, el supervisor de zona escolar, un grupo focal con padres y madres de familia, así como narrativas de diarios de campo y conversaciones informales con personas clave en la escuela. Se realizaron además observaciones en el aula, en el recreo, en la entrada y salida de la escuela y en reuniones formales e informales, como las Juntas de Consejo Técnico Escolar, las asambleas de padres y madres de familia, y demás actividades escolares. La sistematización de la información recabada se realizó con el software Atlas.ti; se diseñaron unidades hermenéuticas en las que se etiquetaron y categorizaron distintos niveles y dimensiones para el análisis.

El objetivo de este artículo es develar cómo la gestión institucional y liderazgo, el involucramiento docente y el familiar en la Escuela Primaria Cuauhtémoc, afectan positivamente de manera directa e indirecta en la eficacia escolar; además, identificar las relaciones cotidianas o interacciones en el entorno escolar y áulico -las cuales se desarrollan en un contexto socioeconómico particular caracterizado como desfavorable--, los valores, actitudes, expectativas, motivaciones, así como los objetivos comunes que están presentes en dichas interacciones entre

2 La investigación se titula "Análisis de alternativas de gestión escolar para superar los efectos de la desigualdad social en el logro educativo", proyecto financiado por el Fondo de Investigación Básica SEP-CONACyT.

Diólo os sobre Educación 
los agentes escolares y sobre los que se construyen acuerdos, negociaciones y la mediación/ resolución de los conflictos.

\section{Estudio de caso: Escuela Primaria Cuauhtémoc Contexto social, cultural y educativo de la comunidad El Bethí}

La comunidad siempre ha sido muy respetuosa, humilde, sigue siendo así la gente, por eso nuestros hijos son así, muy respetuosos, jen El Bethí somos así!

Padre de familia.

El Bethí es una comunidad que se localiza en el municipio de Chilcuautla, en el estado de Hidalgo; tiene una población estimada de 887 habitantes (INEGI, 2020). 97.37\% de sus habitantes pertenecen a la etnia otomí, ${ }^{3}$ de ellos, $74.73 \%$ es hablante de la lengua hñähñu, ${ }^{4}$ que significa hñä: "hablar" y hñu: "nariz", por lo que se puede decir que "las personas que forman el pueblo hñahñu son aquellas que hablan la lengua nasal" (Chapela, 2005: 9).

La comunidad tiene un grado de marginación alto y un índice de rezago social bajo (Sedesol, 2015). En El Bethí hay 307 viviendas, de ellas, 97.72\% cuentan con electricidad y agua entubada, $90.41 \%$ tiene excusado o sanitario, $78 \%$ radio, $72.15 \%$ televisión, $61.19 \%$ refrigerador, $27.85 \%$ lavadora, $30.14 \%$ automóvil, $2.28 \%$ una computadora personal, $7.31 \%$ teléfono fijo, $41.10 \%$ teléfono celular, y $0.91 \%$ internet (INEGI, 2015). Aproximadamente dos terceras partes de los padres y madres de familia de la escuela Cuauhtémoc cuentan con escolarización básica, el resto tienen la primaria inconclusa, algunos no están alfabetizados y un porcentaje menor solo se comunica en la lengua hñahñu (Chapela, 2005).

Gran parte de la población de El Bethí se dedica a las actividades agrícolas, se produce principalmente maíz, frijol, avena, forraje, trigo, calabacitas, cebada, tomate de cáscara, chile verde, nabo y alfalfa verde. En la región se registra una transformación reciente de la actividad agrícola, que ha pasado de ser de subsistencia a la producción de alimentos en invernaderos. Este cambio ha traído empleos formales a El Bethí, aunque algunos se lamentan de problemas de salud asociados al manejo de agroquímicos (Quezada, 2008).

Otra situación que se presenta en la comunidad es la migración a Estados Unidos con repercusiones ambivalentes, porque algunos de los que migraron ayudan económicamente a las

3 Los otomíes constituyen el quinto grupo amerindio de mayor presencia en México y representan $5 \%$ del total de la población indígena en el país. Habitan un territorio discontinuo en el altiplano central mexicano, viven en los estados de Hidalgo, Querétaro, Puebla, Guanajuato, Michoacán, Estado de México, Ciudad de México, Veracruz y un pequeño grupo en Tlaxcala (INPI, 2018; Zimmermann, 1997).

4 El hñähñu pertenece de la familia lingüística otopame, compuesta por el otomí, el mazahua y el pame. Esta lengua cuenta con distintas variantes dialectales entre las que se encuentran el ñätho del Valle de Toluca; el ñäñho de Santiago de Mezquititlán en el sur de Querétaro; el ñsyühü, de la Sierra Norte de Puebla y Pahuatlán, así como el hñähñu del Valle del Mezquital en Hidalgo, donde se encuentra la comunidad de El Bethí (AMLA, 2021). 
familias que se quedan en El Bethí, sin embargo, también sucede que otros no regresan y forman otra familia en el exterior, dejando de apoyar a los hijos, por lo que se constituyen familias monoparentales.

\section{Características de la Escuela Primaria Cuauhtémoc}

"Hablan hñahñu, si no llegas hablando hñahñu no te entiendes con los padres"

Directora de la escuela.

Esta escuela pertenece al sistema educativo federal transferido, las clases tienen lugar en horario matutino. Pertenece a la zona escolar N 092 de Chilcuautla, que atiende 11 centros educativos, todos identificados como escuelas rurales. Para el ciclo escolar 2017-2018 (periodo en el que se realizaron las primeras visitas de trabajo de campo), la matrícula total de la escuela fue de 102 estudiantes.

Es una escuela de organización completa, cuenta con una plantilla de seis docentes, una directora y un intendente. De acuerdo con los datos obtenidos, la primaria Cuauhtémoc tuvo un periodo prolongado sin rotación de personal, es decir, la plantilla docente se mantuvo en el plantel durante varios años, hasta la entrada en vigor de la Reforma Educativa (2012-2018), que motivó las jubilaciones y cambios entre el magisterio.

Durante el ciclo escolar 2018-2019 (en el segundo periodo de trabajo de campo), encontramos una docente de nuevo ingreso al plantel, con apenas unos meses de haber tomado uno de los grupos, tres docentes tienen entre tres y seis años en la escuela y otros dos tienen la mayor antigüedad en el plantel, que es de diez años. La directora, quien cuenta con 26 años dentro de servicio docente, tiene tres años de haberse incorporado a la escuela primaria Cuauhtémoc, tras haber concursado por la plaza.

La población estudiantil que atiende la escuela son hablantes del hñahñu y se comunican en español con sus docentes; el supervisor de la zona escolar, la directora y tres docentes también hablan esta lengua, otros dos maestros señalan que comprenden unas palabras. A pesar de ello, la escuela no pertenece al subsistema de Educación Intercultural Bilingüe (EIB) de la Dirección General de Educación Indígena (DGEI), como señala su directora:

Sí es una escuela indígena, aunque no es considerada en el catálogo de escuelas de aquí como bilingüe, de la modalidad indígena, es general, pero su contexto sí es indígena, es hñahñu. Los papás lo hablan muy bien, los niños lo entienden, lo hablan.

Los entrevistados comentaron que esta comunidad se precia por tener una buena convivencia, y esto caracteriza también a la escuela primaria Cuauhtémoc, se percibe un ambiente de 
seguridad, no se reportan agresiones o faltas graves entre los estudiantes, por el contrario, los docentes destacan la amabilidad y atención con la que son tratados por la comunidad en general y las actitudes de respeto que tienen los estudiantes frente a la figura del maestro o maestra.

\section{Hallazgos}

La tarea es de uno, pero la responsabilidad es de todos: Un modelo de gestión escolar en equipo

"Cuando yo llegué aquí, llegué a una escuela donde los compromisos, los trabajos, las actividades, todo, lo vamos a hacer en conjunto"

Docente.

En la escuela primaria Cuauhtémoc se desarrolla el modelo de gestión escolar que se sigue en todas las escuelas públicas de educación primaria en México, que consiste en la interacción de tres figuras principales: la Dirección Escolar, el Consejo Técnico Escolar y el Comité de Padres y Madres de Familia.

En la dirección recae la responsabilidad principal vinculada a procesos de administración y gestión técnico-pedagógica de los programas y proyectos educativos del centro escolar. El Consejo Técnico Escolar (CTE) es una figura de carácter académico que tiene como finalidad hacer los diagnósticos escolares y diseñar e implementar el proyecto o los proyectos de mejora. En los consejos participa todo el colectivo docente y sesiona una vez al mes, de acuerdo al calendario oficial.

El Comité de Padres y Madres de Familia está constituido por los padres y madres de los estudiantes de la escuela Cuauhtémoc, cuenta con una mesa directiva o de representantes que se renuevan anualmente. El pleno del comité es convocado bimestralmente para dar seguimiento académico de los estudiantes y ofrecer información general de la escuela. La mesa directiva en esta escuela tiene una presencia cotidiana y participativa en las actividades, es el grupo que se encarga de la organización de las familias en las acciones de apertura, cierre, limpieza, mantenimiento y vigilancia de las instalaciones escolares.

En esta escuela se privilegia el trabajo colegiado institucionalizado; la organización para los proyectos que realizan es principalmente en equipo. En general, la directora participa en las reuniones y formas de trabajo bajo la premisa de que "es importante priorizar los resultados y motivar la participación de las personas, 'dando el ejemplo'".

\section{El Consejo Técnico Escolar y otros espacios formales e informales}

de intercambio entre docentes

Un factor en la gestión escolar de la escuela primaria Cuauhtémoc que la investigación identificó como relevante, es el antecedente del liderazgo del director anterior, quien a lo largo de 
diecisiete años en el cargo sentó las bases del trabajo colegiado e instituyó una relación con la comunidad donde la escuela hace parte sustantiva de su dinámica. Este antecedente dejó un estándar alto de desempeño en la gestión, que supone uno de los principales retos para la actual directora, quien reconoce haber recibido una escuela con una estructura y organización completa, activa y altamente comprometida con el buen funcionamiento escolar y con un alto rendimiento académico.

Uno de los hallazgos específicos o particularidades es que el trabajo colegiado, que se institucionalizó en el año 2013 en el formato de las Juntas de CTE, ya se realizaba antes de esa fecha en esta escuela. No era una práctica oficial que fuera dictada por algún programa o estatuto con fecha o calendario específico, pero sí era una actividad institucional interna que consistía en reuniones de trabajo extraescolares que se realizaban cuando el anterior director lo considerara necesario, por lo general no transcurría más de un mes sin que se llevaran a cabo.

Estas reuniones de trabajo las llamamos extraescolares porque, de acuerdo a la información recabada, no se llevaban a cabo en las instalaciones de la escuela, sino que se buscaban espacios alternativos que permitieran salir del entorno rutinario o conocido por los docentes, no implicaban suspensión de clases, pero sí salida anticipada (una o dos horas antes del horario establecido).

Estos encuentros, convertidos en prácticas, fueron promovidos por el director anterior en acuerdo con los docentes, hicieron posible una forma de trabajo en la escuela que permanece como "la tarea es de uno, pero la responsabilidad es de todos", es decir, aun cuando las acciones pueden ser individuales, hay una conciencia en el colectivo docente de que el trabajo de cada uno representa a toda la escuela. Los profesores señalaron que se sienten parte importante de ella y de la comunidad. Esta forma de trabajo basada en la colaboración es el cemento de las acciones y prácticas de la escuela y la nueva directora la ha retomado, lo que redunda en que se mantenga la existencia de lazos de confianza mutua y un ambiente laboral que se vive de proximidad.

Además del tiempo y espacio destinado al CTE, los docentes de la primaria Cuauhtémoc cuentan con un espacio de interacción que es el comedor, donde se reúnen diariamente en el horario de comida. Este espacio, de acuerdo con sus opiniones, les permite el intercambio y puesta en común de problemáticas, retos y situaciones exitosas que se presentan en las aulas. El intercambio cotidiano e informal es considerado por los docentes una práctica clave para el sostenimiento de buenas relaciones entre ellos y para el fortalecimiento del sentido de pertenencia al colectivo y el reforzamiento de los valores y objetivos comunes.

Nos damos el abrazo en la mañana como es escuela chiquita, ahora sí que hay esa integración con los compañeros, nos entendemos. También, hay el respeto, el apoyo cuando es necesario, igual hay esa convivencia, ese clima (Directora de la escuela). 
El clima escolar influye de manera importante en la práctica pedagógica, pues la percepción de los docentes sobre su entorno laboral también está asociado a las actitudes, acciones y prácticas con los estudiantes y al sentimiento de comunidad escolar (Arón, Milicic en Herrera, Rico, 2014). En el caso de la escuela Cuauhtémoc, los docentes, directora y supervisor entrevistados comentaron que las relaciones interpersonales entre ellos son de confianza, de camaradería, de apoyo y colaboración. Dichas relaciones favorecen, por ejemplo, la integración de nuevos miembros al cuerpo docente y relaciones horizontales entre el equipo de trabajo. Todo ello influye en la construcción de un clima escolar sano que favorece la práctica docente, el establecimiento de relaciones armoniosas, la participación de familias y el trabajo colaborativo.

\section{Un liderazgo directivo horizontal y centrado en las personas}

Los docentes opinaron que a la actual directora de la escuela se le reconoce un estilo de liderazgo dinámico, colaborativo, horizontal y humano; los profesores consideran que existe apertura de parte de ella para conocer sus necesidades en el aula, así como los problemas familiares o personales que puedan tener, y se les da prioridad, por encima del cumplimiento del programa a toda costa. Los docentes se sienten reconocidos y escuchados por la directora y saben que, si enfrentan una dificultad que no tiene que ver con sus funciones docentes, recibirán apoyo y comprensión para que estas no se vean afectadas.

Este estilo de liderazgo la directora lo atribuye al entusiasmo y compromiso que tiene por estar iniciando esta etapa profesional y por encontrarse dentro de su propia región geográfica y cultural, lo que la compromete a un nivel más profundo. Es una forma de trabajo que ella misma ha vivido durante su trayectoria, donde ha tenido ejemplos de liderazgo directivo exitosos y también parte de la formación y actualización que ha buscado de manera personal y permanente, participando en cursos y talleres sobre gestión y administración escolar.

Un aspecto relevante para la gestión adecuada de las necesidades y de las tareas de la escuela es el conocimiento del contexto, ya que esto fue lo primero que hicieron notar los docentes a la directora cuando se incorporó; identificaron que a pesar del entusiasmo y las ganas de elaborar proyectos escolares ambiciosos, las condiciones económicas de las familias de la comunidad no permiten hacer una solicitud constante de materiales o recursos que no pueden absorber. El éxito de la gestión, consideran los participantes, recae en este reconocimiento y escucha de todos los involucrados en el funcionamiento de la escuela.

La directora sostiene que "ella es una docente más en la escuela", pero con funciones directivas en las que intenta nunca dejar atrás lo pedagógico, aun cuando pueda ser muy absorbente lo administrativo. Una de las actividades que desarrolla con particular interés es hacerse cargo de los grupos cuando los docentes deben ausentarse por diferentes motivos, por una parte, esta actividad le permite volver a la práctica docente que desarrolló por veintitrés años, y por otra, tomar el pulso a los grupos, conocer sus fortalezas y áreas de oportunidad para apoyar a los docentes. 
Esta apertura de la directora al trabajo frente a grupo es reconocida por los docentes; mencionaron sentirse respaldados por ella ante cualquier situación imprevista que les impida estar en el aula, también sienten confianza de que se haga cargo de los grupos cuando sea necesario porque saben que tiene una amplia experiencia, la sienten cercana por esta acción que lejos de ser de vigilancia, es una muestra de apoyo y trabajo en equipo.

Una de las actividades por las que la directora actual ha recibido apoyo y reconocimiento de la comunidad educativa es la decisión de crear un pequeño museo en las antiguas instalaciones de la cárcel comunitaria. La iniciativa fue de un grupo de padres y madres de familia, pero la directora asumió la actividad como un reto, se propuso recrear la historia comunitaria para preservar la cultura y transmitir a la generación estudiantil actual algunos aspectos de su identidad. Para impulsar el proyecto y motivar la participación de los docentes, estudiantes y familias, la directora inició las labores manuales que se requerían para que el museo se pusiera en marcha, según expresó en la entrevista decidió "ser ella misma" y ponerse a trabajar.

\section{Anticiparse a los conflictos: transparencia y rendición de cuentas}

La escuela primaria Cuauhtémoc no está exenta de conflictos que pueden surgir, sobre todo por la estrecha relación que hay en la comunidad y las altas expectativas que tiene la población en cuanto al desempeño del personal de la escuela, pueden darse malentendidos por "no cumplir su palabra" o no dar informes de las actividades "según lo acordado". La directora recordó que, en una ocasión, por exceso de trabajo, no informó sobre una actividad acordada y percibió que esto había causado malestar, por lo que antes de que se hiciera más grande el problema, se comunicó con la comunidad escolar y les ofreció una disculpa por la falta de comunicación oportuna, y les agradeció su comprensión.

En sus propias palabras, la directora trata de prestar atención a todas las inconformidades que pueden darse, darles la debida atención por pequeñas que sean y anticiparse al surgimiento de un conflicto. Comunicación asertiva, transparencia en las acciones y una constante rendición de cuentas, son la clave de lo que considera una gestión adecuada y comprometida con el mejoramiento común.

Con la información recabada y el análisis en profundidad desde los niveles micro y meso, se puede confirmar que la escuela primaria Cuauhtémoc es una organización con alta eficacia escolar, debido al modelo de gestión y liderazgo que se practica; se nota una construcción cotidiana de consensos que, sin estar exenta de tensiones, no llegan a conflictos graves. Sobre todo, están ausentes pugnas que pongan en riesgo el clima escolar que se ha consolidado durante muchos años, sobre todo en lo que toca a los objetivos y compromisos de los agentes escolares y de estos con las familias. 


\section{Un cuerpo docente comprometido con los estudiantes y con la cultura indígena}

"La verdad es muy bonito estar aquí"

Docente.

Para aproximarnos al ámbito del involucramiento docente recuperamos prácticas y trayectorias profesionales de los docentes, así como percepciones de padres y madres de familia. Indagando particularmente en las motivaciones, expectativas, retos y logros del colectivo docente, identificamos actitudes y acciones relevantes hacia los estudiantes y hacia el contexto, como la empatía con el otro, el compromiso colectivo (que trasciende lo individual) y el reconocimiento de sí mismos como agentes de cambio social.

El compromiso de los docentes con los aprendizajes de los estudiantes es un pilar de la escuela y emerge de las bases que han construido docentes y directivos durante años, esto ha sido reforzado por el interés compartido que tienen los familiares de que sus hijos aprendan con bienestar. El espíritu comunitario también contribuye a que los logros y aportaciones sean principalmente visualizados por los docentes como parte del colectivo, lo que trasciende la aportación individual.

\section{Cumplimiento y compromiso de los docentes con el aprendizaje de los estudiantes}

El primer indicador de que los docentes de la escuela primaria Cuauhtémoc se encuentran comprometidos con su trabajo es que hay un cumplimiento estricto del horario y que, de acuerdo a los padres y madres de familia, es poco común que se suspendan clases injustificadamente o se ausenten los docentes. La percepción generalizada de los padres y madres es que "en la escuela se trabaja", lo que les proporciona tranquilidad porque sus hijos e hijas están aprendiendo; también comentaron que los docentes son respetuosos, atentos y preocupados por el bienestar de los niños:

Los docentes son responsables de su trabajo y son puntuales. Si a las ocho se entra, pues a las ocho y tienen su hora de salida. Tienen respeto a los alumnos [...] Y a veces, se quedan una hora más, se van yendo más o menos a las dos de la tarde. Entonces, sí hay un poquito más de ellos hacia los alumnos [...] Tienen más compromiso con su trabajo (Madre de familia).

Otro indicador tiene que ver con un marcado interés del colectivo docente en que los estudiantes alcancen los aprendizajes esperados, de acuerdo a la etapa o grado que cursen. Identificamos prácticas sobresalientes en el ámbito de la evaluación que ponen de manifiesto que hay una preocupación porque el estudiante "salga adelante", como ellos mismos mencionan. Una de ellas es la aplicación regular del Sistema de Alerta Temprana o SISAT, que consiste en 
evaluaciones diagnósticas que ayudan a la detección de problemáticas asociadas a operaciones matemáticas y comprensión lectora.

La aplicación regular de este diagnóstico es una iniciativa de la directora, ya que el programa educativo solo contempla aplicaciones de inicio y de cierre de ciclo escolar; los docentes han adoptado la iniciativa de manera exitosa y la valoran positivamente dentro de su práctica. Ello les ha permitido hacer cambios de ruta en los proyectos de mejora con la finalidad de regularizar a los estudiantes cuando baja su desempeño en alguna de estas dos áreas.

EI SISAT, esta plataforma o programa, Sistema de Alerta Temprana, es algo que se debe de hacer en todas las escuelas atendiendo la mejora escolar, la prioridad de los aprendizajes. Todos los tenemos que hacer precisamente para mirar las principales habilidades que son lectura, escritura y cálculo iy cómo nos ayudan! Sin estos instrumentos, a lo mejor divagaríamos, pero, nos va llevando de la mano (Directora de la escuela).

Adicionalmente a estas prácticas, algunos docentes comentaron que la evaluación en ocasiones no refleja de manera directa el verdadero aprendizaje del estudiante, por lo que es importante contextualizar la enseñanza, ofrecer oportunidades para que aterricen sus conocimientos a la vida cotidiana:

Todo el tiempo llevo mi registro por tarea, por materia. Entonces, tengo que hacerlo diario, porque es un aprendizaje que ellos tienen. Son chicos que tienen ese contexto y no tienen malicia y, la verdad, a mí en lo personal me da gusto trabajar con ellos. La tarea que yo siempre les dejo es palabras, preguntas de lo que vamos a ver mañana porque no puedo hablar con ellos si no entienden de qué palabras estamos hablando (Docente).

Un hallazgo relevante es que los profesores de la escuela hablan de los aprendizajes de los estudiantes y consideran que el sentido de su trabajo está en el logro que ellos puedan alcanzar de manera individual, no hacen referencia al éxito en las pruebas estandarizadas, en las competencias de conocimientos o en que obtengan altos puntajes en las evaluaciones. El centro de su trabajo es el estudiante y su aprendizaje.

El aprendizaje centrado en el estudiante es considerado esencial para mejorar la calidad de la educación (Delgado, 2019). Los profesores de la primaria Cuauhtémoc señalaron que lo importante para ellos es que los estudiantes adquieran conocimientos y habilidades para la vida, para ello utilizan métodos innovadores, promueven el trabajo en equipos, practican una comunicación asertiva con los estudiantes; factores que la literatura especializada ha mencionado de gran importancia para el logro escolar (Bellei et al., 2014).

Los profesores comentaron que tienen expectativas altas de sus estudiantes, esperan que sean profesionistas y que alcancen sus metas académicas: 
En el futuro yo espero que sean profesionistas, así espero yo y así se los hago ver. Por ejemplo, varios niños, me decían "maestro yo quiero ser como usted" [...], tienen esa visión y tienen que saber que esto cuesta y que cuesta todo y que ahorita nada más hay que saber echarle ganas a la escuela porque esto es la clave del éxito, estudiar y estudiar, les digo eso que aprenden es para que se defiendan cuando sean grandes (Docente).

Según Zorrilla, (2002) y Murillo et al., (2011), el mantenimiento de altas expectativas académicas en los estudiantes por parte de docentes y familias es un elemento característico de las escuelas eficaces. Para Bellei et al., (2014), la concordancia y sintonía que tienen los profesores en las escuelas y las familias en sus hogares sobre el mantenimiento y promoción de expectativas académicas de los niños y niñas fortalece el trabajo conjunto y refuerza los lazos de confianza con la comunidad escolar. En la escuela Cuauhtémoc, el entusiasmo de los docentes ha contagiado también a los padres y madres de familia, e incluso escuchamos esta motivación en la supervisión escolar.

Los profesores de esta escuela señalaron que realizan la planeación didáctica porque les sirve de gran apoyo a la hora de cumplir con los objetivos; la elaboran de manera semanal o mensual; además, les sirve para identificar los avances que van teniendo y buscan información por diversos medios para ejercer su trabajo con la mayor calidad. Otros comentan que la planeación es importante, pero se realizan siempre adaptaciones al implementarla, para adecuar los contenidos a la realidad que viven sus estudiantes y que esto enriquece su trabajo pedagógico.

El jueves les dije: "saben qué, necesito una báscula para trabajar los gramos, los kilogramos" y sí hay disposición, porque la trajeron y a ellos les interesa, pero trato de involucrarlos a lo que viven, esa es la clave (Docente).

Durante las observaciones en el aula, en la mayoría de los salones se distinguieron láminas construidas por los propios docentes y por sus estudiantes, materiales diversos como: maquetas, abecedarios, láminas de números, mapas, libros de textos, cuentos, dibujos, y en las aulas de grados superiores había espacios para hacer experimentos. Algunos profesores realizaban dinámicas y actividades lúdicas con los estudiantes como cantos, juegos y actividades fuera del aula de clases.

En otros salones se observaron dinámicas que fomentaron el aprendizaje de los contenidos que se estaban desarrollando. Algunos ejemplos eran muy concretos acerca de situaciones cotidianas, lo que facilitaba que los estudiantes se mantuvieran motivados. Un docente comentó que utilizan los libros de texto como un apoyo, pero que es más importante que los estudiantes comprendan lo que viene en el libro mediante ejemplos prácticos. 


\section{Cultura comunitaria y contexto desde la perspectiva de los docentes}

Lo principal es que recobren [los estudiantes] la identidad cultural, que la reconozcan, la valoren y no se pierda, porque en estas generaciones se está perdiendo la lengua, y está en nosotros la responsabilidad que no sea así

Directora.

Otro indicador de involucramiento y compromiso del cuerpo docente con la comunidad escolar es el que demuestran a través de actitudes de reconocimiento y respeto por la cultura y la lengua local. Esto es notable ya que, al tratarse de una escuela general, que no tiene el mandato o la obligación de cumplir con un programa bilingüe o intercultural como las escuelas pertenecientes a la DGEI, queda a juicio de los docentes realizar actividades de fortalecimiento identitario o lingüístico.

He querido yo como maestro que no decaiga esto [la cultura indígena]. Hablar con ellos, decirles que esta lengua es muy bonita, la autoestima subírsela porque finalmente se va perdiendo, pero sí deseo hablar y nos comunicamos con los papás igual. Entonces, eso cambia mucho (Docente).

Este interés converge con el argumento de Zorrilla (2002), quien señala que la acción docente, aunque esté ubicada en el aula y en la escuela como instalaciones físicas, no deja de ser importante que también se contemple el contexto más amplio en el cual se sitúa, en este caso en la comunidad de El Bethí y su cultura.

Los docentes manifiestan reconocimiento hacia la cultura hñahñu y hablan en diferentes momentos la lengua con sus estudiantes y familias. Se realizan saludos y se facilitan las orientaciones en la lengua originaria. Durante la práctica docente también desarrollan elementos culturales propios con actividades que involucran cuentos, leyendas, cantos e historias en su lengua materna. Se puede decir que los profesores de la escuela primaria Cuauhtémoc tienen en cuenta el contexto intercultural y bilingüe de la comunidad para diseñar su planeación y desarrollar las clases. Esta consideración se repite a lo largo de la práctica docente en varios momentos que pudimos observar directamente.

\section{Arraigo a la región y empatía con los estudiantes}

En la exploración que se hizo de la trayectoria de los docentes, así como de algunas de sus motivaciones y expectativas dentro su ámbito profesional, podemos destacar que existe un arraigo a la que consideran "su propia región"y "su misma gente" al referirse a los miembros del grupo étnico hñahñu. Para muchos de ellos, después de trabajar en regiones apartadas o de difícil acceso, encontrarse en El Bethí es un logro, debido a los elementos culturales y lingüísti- 
cos que comparten. Trabajar para su mismo grupo étnico, en una escuela en la que se vive y se respeta la diversidad cultural, es un factor de cohesión y compromiso del colectivo docente de la escuela Cuauhtémoc, más allá del compromiso que se puede tener con un buen desempeño profesional.

También se identifica en los testimonios de los docentes cierta empatía hacia las condiciones y retos que enfrentan los niños y niñas de las comunidades rurales e indígenas. Como narran, algunas etapas de su desarrollo académico estuvieron marcadas por su diferencia étnica y por momentos en los que sufrieron alguna clase de discriminación o enfrentaron mayores dificultades que sus pares no indígenas.

Desde sus historias personales y en el momento actual, reconocen que sus estudiantes tienen mayores desafíos en la sociedad que quienes no pertenecen a un grupo étnico, porque la discriminación es un hecho social innegable, por ello sienten un compromiso mayor y una empatía con su alumnado, pues saben que "salir adelante" o "superarse" es un reto que ellos experimentaron en su propio trayecto de vida.

\section{Los padres y madres de familia de la escuela primaria Cuauhtémoc: corresponsabilidad} y participación

"Maestra, ¿le falta algo?"

Padre de familia.

"Estamos enseñando a nuestros hijos, a lo mejor no somos la excelencia, pero queremos ser ejemplo para ellos" Madre de familia.

El involucramiento familiar es uno de los componentes que en este estudio de caso nos ofrece más riqueza y amplitud de prácticas y posicionamientos de los distintos actores frente a la institución escolar y su función social. La identificación con la escuela y la apropiación del espacio son factores destacables en cuanto a este eje de análisis, así como la participación equitativa de los padres y madres, y su fuerte sentido de corresponsabilidad con todo lo que sucede en la escuela.

Uno de los rasgos notables de la relación de las familias con la escuela es que no la perciben como una institución gubernamental ajena a la comunidad, sino que es un espacio comunitario gestionado por una instancia de gobierno y por la misma población, por lo que las familias de El Bethí sostienen, ante todo, que "la escuela es nuestra".

\section{La escuela es nuestra: identificación con el espacio escolar y apropiación}

De acuerdo con las informaciones obtenidas en la escuela Cuauhtémoc, históricamente ha habido participación de los padres y madres de familia, algunas personas entrevistadas señalaron 
que los habitantes de El Bethí siempre han estado preocupados por la escuela, les gusta participar activamente y atender las necesidades que se presentan.

La gente de aquí es muy unida. Entonces, aquí no hay problemas de esos que, de robos, de violencia. No, aquí la gente es unida. Siempre se ha dicho que a la gente que llega se le recibe con las manos abiertas, con respeto (Madre de familia).

Las formas de organización comunitaria que practican tienen larga data e inciden en la organización escolar, por ejemplo, el no cumplimiento de las acciones acordadas en el Comité de Padres y Madres de Familia va acompañado de sanciones, las cuales son impuestas por las autoridades de la comunidad y van desde acuerdos, multas, hasta encarcelamiento 5 según las normas comunitarias.

Hay acuerdos y se hacen cumplir, todavía me toca ver cómo hacen cumplir al que queda como comité y si no cumple pasa al delegado y paga su sanción por no haber hecho de la mejor manera el cargo que le ha conferido. Entonces, eso se da y yo los entiendo. Otros dirían ¡Ah, todavía se da eso! No los encierran ya, pero sí tienen que aportar. Y es bonito porque solo así saben salir adelante, son medios, es una forma (Directora).

Cuando algunos padres y madres de familia entrevistados compartían cómo se procede con las sanciones del comité, recordaban que la propia comunidad de El Bethí es conocida por lo que ellos Ilaman "acuerdos comunitarios", y que esta forma de organización comunal les ha servido para prevenir abusos, robos y situaciones de violencia que amenazan el orden, la paz y seguridad de las familias.

Antes aquí era una delegación y la bóveda, esa esa era la cárcel... A personas que desobedecían y a alumnos, los que desobedecían eran castigados ahí. Ese era un acuerdo de la comunidad que se tenía que hacer, esto para ver si aprendían de palabra a palabra, porque a lo mejor al momento sí, pero al rato pues..., hubo alguien que dijo que teníamos que ver la manera de ver cómo los castigábamos y, ¡si hablara esa bóveda! (Padre de familia).

Un número importante de padres y madres de familia de la escuela Cuauhtémoc cursaron su educación primaria en las instalaciones actuales, durante su participación en esta investiga-

5 En el pasado, entre las costumbres de la comunidad de El Bethí se contempló el encarcelamiento como forma disciplinaria, por suerte este proceder ya no está considerado en la escuela y una expresión positiva de este cambio es que lo que era la prisión en la actualidad es el museo de la escuela. 
ción, recurrieron comúnmente a sus recuerdos y experiencias en el mismo espacio; podemos decir que hay una identificación personal y colectiva con la institución escolar, es parte de la historia comunitaria y sus transformaciones reflejan, asimismo, las transformaciones de la comunidad.

Actualmente los padres y madres se organizan para cuidar y vigilar la escuela durante el día y las noches. Algunos entrevistados coinciden en que a los habitantes de El Bethí les gusta participar en el comité para cuidar la escuela, limpiarla y atender las necesidades que se presentan, todo ello demuestra el compromiso y el grado alto de implicación de las familias con el centro educativo.

De la escuela aquí vigilan en las noches. El comité en turno se queda en la noche, les toca su turno en el día, venden sus dulcecitos para apoyar sus necesidades, pero están dispuestos: "Maestra, ¿le falta algo?"... Es más, no duermen vigilando el turno, se van a las cinco de la mañana y ya felices de haber cumplido (Directora).

La función de nosotros ahora que estamos en el papel del comité, bajo nuestra responsabilidad es ver nuestra escuela, cuáles son las necesidades que hay. Nosotros estamos tras de ellos, ¿qué es lo que le hace falta?, y pues ahí estamos. A lo mejor no lo estamos haciendo al cien, pero estamos al pendiente de la escuela, si se necesita remodelar, eso es lo que estamos al pendiente. Hay ahora cositas que nos hacen falta como cañones, pues sí nos hace falta (Padre de familia).

Estas acciones de cuidado y vigilancia de la escuela se cumplen de manera estricta por parte del comité y pudimos observar que son llevadas a cabo con agrado, es poco común que algunas familias no cumplan con la tarea, cuando esto sucede debe estar justificado y por lo general se hace un pago económico para cubrir el reembolso a otra persona que lo realice.

La escuela es nuestra es algo más que una frase para las familias de El Bethí, ellos asumen que el cuerpo docente, las autoridades educativas y el gobierno en general, son figuras temporales, con un compromiso limitado por el tiempo que se le asigne a la escuela o a su cargo. En cambio, la comunidad, las futuras generaciones siempre estarán ahí y necesitarán un espacio digno para recibir educación, es por ello que los padres y madres están apropiados no solo del espacio que cuidan como bien común, sino también de lo que la escuela simboliza como centro de socialización, crecimiento y aprendizaje para sus hijos e hijas.

En resumen, se puede decir que el compromiso hacia las familias en el proyecto educativo de la escuela Cuauhtémoc es alto. La participación de los padres y madres de familia favorece que la escuela obtenga recursos para poder mejorar sus instalaciones y realizar otras actividades. Ante esto, se puede decir que el contexto de la comunidad de El Bethí y su tradicional forma de organización, favorece el proyecto educativo de la propia escuela. 


\section{Corresponsabilidad}

Sobre las relaciones con padres y madres de familia en la escuela, los docentes y la directora, en las entrevistas comentan que mantienen una relación cercana con ellos, se han suscitado conflictos, pero son situaciones que se han atendido en su momento de forma oportuna. Al entrevistar a padres y madres de familias sobre este tema, muchos comentaron que reconocen y les agrada que los docentes hablen su lengua, que siempre tengan disponibilidad para atenderlos y perciben el compromiso que estos tienen, por eso los apoyan.

Es lo importante de aquí, porque hay padres de familia que no entienden bien el español y puede hablar con padres de familia [la directora y los docentes]. Yo creo que la mayoría de los maestros que trabajan aquí sí saben, se interesan por el lenguaje de aquí (Madre de familia).

Algunos docentes comentaron que, aunque muchos padres y madres no hablan español, solo la lengua hñañhu, ello no impide que participen, que tengan comunicación con ellos y con la directora. Que los docentes hablen también esta lengua afianza las relaciones con las familias, generando que la comunidad escolar esté unida en el proyecto educativo de la escuela primaria Cuauhtémoc.

Por lo general vienen mucho [los padres y madres], aunque depende del maestro, pero yo trato de que estén todos y que se den cuenta de cómo van sus hijos, pero sí, casi no tengo problema de que estén todos (Docente).

Para Valdés et al., (2009), uno de los factores que más influye en el desempeño escolar son las prácticas familiares, incluso por encima de los aspectos demográficos, económicos y comunitarios que rodean al estudiante. Por ello para la mejora de la calidad de la educación es indispensable lograr una interacción efectiva entre los padres, madres de familia y los docentes. La participación de padres y madres en la escuela Cuauhtémoc, como se mencionó en el apartado anterior, es activa y comprometida. La motivación constante, el respeto asumido por la autoridad del docente, el mantenimiento de expectativas y aspiraciones altas, así como la conciencia del valor de la escuela, hacen que los estudiantes, sus familias y el colectivo docente se encaminen hacia la búsqueda constante del logro académico, lo que también es un elemento característico de las escuelas con alta eficacia escolar (Báez, 1994; Bellei et al., 2004, 2014; Murillo et al., 2011; Zorrilla, 2002).

Las formas de organización y participación comunitaria se traducen en la escuela Cuauhtémoc en una implicación voluntaria y activa de los miembros de la comunidad escolar. Los esquemas utilizados incluyen la participación de todos -no en el mismo tiempo y forma-, el 
reparto de tareas de forma equitativa, la rotación, el apoyo comprensivo ante emergencias o la imposibilidad de realizar el trabajo.

La responsabilidad con la escuela es como con una casa, si se pierde algo aquí y la gente sabe que ustedes fueron nombrados, son los papás los responsables. El presidente de la asociación aquí, padre de familia, es quien organiza y dice "ustedes van a ser, ustedes los próximos" y así, la rueda cambia (Padre de familia).

Como se puede constatar, el comité cumple sus tareas con un sentido de responsabilidad que perciben como una tarea compartida que tienen con el personal de la escuela, es la tarea de que la escuela funcione bien y sus hijos e hijas aprendan. Es por ello que en este eje de involucramiento familiar hablamos de corresponsabilidad, porque hay un claro reparto de tareas que los padres y madres perciben como la parte que a ellos les toca porque el beneficio directo es para sus niños, no para el docente o la directora.

Como dicen los maestros: "yo soy papá mediodía, tú eres papá mediodía también"y eso es lo que hemos trabajado en conjunto..., yo trato de colaborarme con ellos también y llamar a los papás que ayuden, ¿quiere ver a sus hijos superados? "échenle la mano" y esto es lo que nos ha ayudado también, porque la comunicación es lo que cuenta muchísimo (Padre de familia).

Los padres y madres de familia de esta escuela asumen que un elemento imprescindible para el buen desarrollo de las actividades es la comunicación directa, lo que permite coordinarse, resolver conflictos, establecer acuerdos, sanciones, y en general, mantener cercanía entre las familias, otras instituciones y la escuela.

\section{Conclusiones y reflexiones finales}

A partir del análisis realizado de los tres niveles o ejes, gestión institucional, involucramiento docente e involucramiento familiar, identificamos diferentes prácticas, actitudes y valores que inciden en la eficacia de este centro educativo. En resumen, se destacan las siguientes:

a) Liderazgo directivo con buena competencia técnica, compromiso social y comunitario, sensibilidad y buen manejo de las relaciones interpersonales, así como buenas prácticas en la gestión de recursos (transparencia en su manejo y rendición de cuentas).

b) Colectivo docente que prioriza el aprendizaje de los estudiantes, de los que tienen altas expectativas, que practica constantemente el diagnóstico escolar y de aula como instrumento para la mejora de sus resultados, sensibilizado y empático con el contexto sociocultural de los estudiantes y con arraigo en la región. 
c) Familias apropiadas del ámbito escolar como espacio público-comunitario, que participan activamente en la gestión y resguardo de recursos para la escuela y que exigen el cumplimiento a la institución de su deber (cumplir con el horario, no suspender clases, etcétera).

La pertenencia étnica es un componente que cohesiona a la mayoría de involucrados en el funcionamiento escolar. Existe un posicionamiento compartido entre el colectivo docente y la directora de que trabajan para su misma gente lo que se entiende como un lazo entre un grupo étnico minoritario que les da pertenencia e identidad.

La búsqueda del bienestar común, posicionamiento que subyace en las formas de organización comunitaria tradicionales como la que se mantiene entre los otomíes de El Bethí, es uno de los valores presentes en las formas de trabajo y participación que documentamos y observamos. En este sentido, la escuela funciona como un reflejo de la realidad comunitaria y familiar anclada fuertemente en las prácticas o costumbres de los grupos rurales e indígenas menos expuestos a las formas de relación individualista de la sociedad mayoritaria o mestiza.

Lo que puede percibirse como una limitante o carencia, como por ejemplo la falta de dispositivos electrónicos o de acceso a internet, también mantiene formas de trabajo creativas y comprometidas por parte de la directora y los docentes, que buscan igualar las oportunidades de sus estudiantes de tener una educación de calidad como la que tienen los sectores más favorecidos.

De acuerdo a lo que este caso nos revela, una educación de calidad, que posibilita el buen desempeño de los estudiantes en las pruebas estandarizadas, es la que acerca al estudiante a los conocimientos y habilidades necesarios para la vida, reconociendo el contexto y características socioculturales que condicionan sus aprendizajes.

Este condicionamiento, que puede ser favorable o desfavorable según se mire, en el caso de la escuela primaria Cuauhtémoc, es un detonante para que la educación en su forma escolarizada sea un reto para todos y que se asuma en forma de compromiso con la igualdad de oportunidades y con el derecho humano fundamental a una educación de calidad y, sobre todo, que mejore las expectativas de desempeño económico de la población. Esto último es una motivación fundamental tanto para los actores institucionales (directora y docentes), como para los actores comunitarios.

\section{Referencias}

Acevedo, C.; G. Valenti; E. Aguiñaga (2017). Gestión institucional, involucramiento docente y de padres de familia en escuelas públicas de México. Calidad en la Educación, 2(46), 53-95. https://www.calidadenlaeducacion.cl/index.php/rce/article/view/3/3 
AMLA (2021). Las lenguas indígenas de México: Otomí. https://www.amla.org.mx/otomi/

Báez, B. (1994). El movimiento de escuelas eficaces: Implicaciones para la innovación educativa. Revista Iberoamericana de Educación, 1(4), 93-116. https://doi.org/10.35362/rie40435

Bellei, C.; G. Muñoz; L. Pérez; D. Raczynski (2004). ¿Quién dijo que no se puede? Escuelas efectivas en sectores de pobreza. Chile: Ministerio de Educación de Chile-UNICEF. https://www.unicef.cl/centrodoc/escuelas efectivas/escuela\%20efectivas.pdf

Bellei, C.; J. Valenzuela; X. Vanni; D. Contreras (2014). Lo aprendí en la escuela ¿Cómo se logran procesos de mejoramiento escolar ? Chile: Universidad de Chile-UNICEF.

http://www.ciae.uchile.cl/docs/LoAprendiEscuela/libro/B Loaprendienlaescuela/mobile/index.html

Blanco, E. (2009). Eficacia escolar y clima organizacional: apuntes para una investigación de procesos escolares. Estudios Sociológicos, 27(80), 671-694. https://estudiossociologicos.colmex.mx/index.php/es/article/view/296/296

Chapela, L. (2005). Ventana a mi comunidad. Cuadernillo cultural. El pueblo hñahñu. https://books.google.com.mx/books?id=yww2UICSolIC\&printsec=copyright

Collins, R. (2009). Cadenas de rituales de interacción. España: Anthropos.

Delgado, L. (2019). Aprendizaje centrado en el estudiante, hacia un nuevo arquetipo docente. Enseñanza \& Teaching: Revista Interuniversitaria de Didáctica, 37(1), 139-154. https://doi.org/10.14201/et2019371139154 Goffman, E. (1970). Ritual de la interacción. Argentina: Tiempo Contemporáneo.

Hernández, R.; F. Murillo; C. Martínez (2014). Factores de ineficacia escolar. Revista Iberoamericana sobre Calidad, Eficacia y Cambio en Educación, 12(1), 103-118.

https://www.redalyc.org/pdf/551/55129541007.pdf

Herrera, K.; R. Rico (2014). El clima escolar como elemento fundamental de la convivencia en la escuela. Escenarios, 12(2), 7-18. https://doi.org/10.15665/esc.v12i2.311

INEE (2014). El derecho a una educación de calidad. Informe 2014 (Vol. 0). México: INEGI. https:// www.inee.edu.mx/wp-content/uploads/2018/12/P1D239-1.pdf

INEGI (2015). Estimaciones a nivel municipal. México: INEGI.

https://www.gob.mx/cms/uploads/attachment/file/239924/05-cuadro-01.pdf

INEGI (2020). Censo de población y vivienda 2020. México: INEGI.

https://www.inegi.org.mx/app/scitel/Default?ev=9

INPI (2018). Atlas de los pueblos indígenas de México. México: INPI. http://atlas.inpi.gob.mx/

Martínez, C. (2012). 25 Investigaciones clave en eficacia escolar. Profesorado Revista de Curriculum y Formación del Profesorado, 15(3), 149-174. https://recyt.fecyt.es/index.php/profesorado/article/view/41458

Martínez, C. (2015). Investigación sobre enseñanza eficaz. Un estudio multinivel para Iberoamérica. Aula de Encuentro, 19(2), 220-223.

https://revistaselectronicas.ujaen.es/index.php/ADE/article/view/3491 
Martínez, C.; F. Murillo (2016). Investigación Ibero-Americana sobre enseñanza eficaz. Revista Mexicana de Investigación Educativa, 21(69), 471-499. http://www.comie.org.mx/documentos/rmie/v21/n069/pdf/69005.pdf

Murillo, F. (2006). Estudios sobre eficacia escolar en Iberoamérica. 15 buenas prácticas. Convenio Andrés Bello. https://issuu.com/guerrerortiz/docs/eficaciaescolar2-murillo 2007

Murillo, F.; C. Martínez; R. Hernández (2011). Decálogo para una enseñanza eficaz. Revista Electrónica Iberoamericana sobre Calidad, Eficacia y Cambio en Educación, 9(1), 6-27. https://revistas.uam.es/reice/article/view/4715/5149

Quezada, M. F. (2008). La migración hñähñú del Valle del Mezquital, Estado de Hidalgo. México: Comisión Nacional para el Desarrollo de los Pueblos Indígenas.

Sedesol (2015). Catálogo de localidades. Microrregiones. El Bethí. México: Sedesol. http://www.microrregiones.gob.mx/catloc/contenido.aspx?refnac=130190002

Valdés, Á.; M. Pavón; P. Sánchez (2009). Participación de los padres de alumnos de educación primaria en las actividades académicas de sus hijos. Revista Electrónica de Investigación Educativa, 11(1), 1-17. http://redie.uabc.mx/vol11no1/contenido-valdes.html

Zimmermann, K. (1997). La descripción del otomí/hñahñu en la época colonial: Lucha y éxito. En Vervuert Iberoamericana. España: Separata.

Zorrilla, M. (2002). ¿Qué relación tiene el maestro con la calidad y la equidad en educación? Calidad y Equidad en Educación en la Escuela Normal Rural "Raúl I. Burgos" de Ayotzinapa, Guerrero. http://www.oei.es/docentes/articulos/relacion maestro calidad equidad educacion zorrilla.pdf 